\title{
Performing Corneal Collagen Cross-linking after Radial Keratotomy in a Patient with Keratoconus: Case Report
}

\author{
Mehmet Ozgur Cubuk, ${ }^{1}$ (1) Kamil Bilgihan² \\ 1Department of Ophthalmology, Istanbul Training and Research Hospital, Istanbul, Turkey \\ ${ }^{2}$ Department of Ophthalmology, Gazi University, Ankara, Turkey
}

\begin{abstract}
To present a case with progressive keratoconus after treated with radial keratotomy (RK) and was undergone corneal collagen cross-linking $(\mathrm{CXL})$ for preventing the progress of keratectasia.

A progressive keratoconus case who was previously treated with RK was undergone corneal collagen cross-linking (CXL) in her left eye for preventing the progress of keratectasia. After the CXL procedure performed at another clinic, best-corrected visual acuity (BCVA) of her left eye decreased from 0.9 to 0.6 Snellen lines in an 8-months follow-up. Pre CXL maximum keratometric power (P-Kmax) was also increased from 52.1 to 57.16 Diopter (D) in the eight months after CXL. Applying CXL on the keratoconic patient previously treated with RK should be questioned.

Keywords: Corneal cross-linking, radial keratotomy, keratoconus.
\end{abstract}

\section{Introduction}

Keratoconus (KC) is a noninflammatory, usually bilateral corneal disease with a cone-shaped corneal protrusion, apical thinning, and irregular astigmatism and is associated with central scarring at the cornea (I, 2). Radial keratotomy (RK) was a crucial procedure in the history of refractive surgery and was the basic method used to treat patients with mild to moderate myopia (3). A long-term follow-up of patients treated with RK has shown corneal instability and frequent hyperopic shifts, yet corneal ectasia after RK is an uncommon complication (4-7). Moreover, RK was used for treating keratoconic patients, and frequently unfavorable results were observed for treating keratoconic patients with RK in the literature (8-10). Corneal collagen cross-linking (CXL) is a new method for preventing the progress of keratectasia, such as keratoconus and secondary corneal ectasias (6). We present a case with progressive keratoconus after treating with RK and undergoing CXL to prevent the progress of keratectasia.

\section{Case Report}

A 28-year-old woman was presented to the Department of Ophthalmology at the Gazi University Hospital. She had experienced progressive visual impairment in the left eye for eight months. The patient reported a history of bilateral keratoconus treated with RK at another center eight years previously, and her visual impairment had progressed, particularly in her left eye for the last two years after the RK procedure. Therefore, the patient was diagnosed as having a progression of keratectasia and had undergone the CXL procedure in her left eye to prevent the progress of keratectasia at another clinic. According to the patient's previous doctor, the standard CXL procedure with a hypotonic riboflavin so-

Address for correspondence: Mehmet Ozgur Cubuk, MD. Istanbul Egitim ve Arastirma Hastanesi, Goz Hastaliklari Klinigi, 34010 Zeytinburnu, Istanbul, Turkey

Phone: +90 5057901038 E-mail: mehmetozgurcubuk@yahoo.com

Submitted Date: May 11, 2019 Accepted Date: September 01, 2019 Available Online Date: December 27, 2019

${ }^{\circ}$ Copyright 2019 by Beyoglu Eye Training and Research Hospital - Available online at www.beyoglueye.com OPEN ACCESS This work is licensed under a Creative Commons Attribution-NonCommercial 4.0 International License. 
lution was applied to the patient. Her pre- and post-CXL refractive errors and best-corrected distance visual acuity values (BCVA) are shown in Table I. Her slit-lamp examination revealed eight well-healed RK scars in the right eye, nearly at $90 \%$ corneal thickness, and 10 similar incisions in the left eye of two had separated wound lips in the temporal part (Figs. Ia, 2a, b). Her intraocular pressure (IOP) measured by Goldmann applanation tonometry was $12 \mathrm{~mm} \mathrm{Hg}$ in both eyes and her fundus examination was normal.

Pre-CXL scanning-computerized (Orbscan, Bausch \& Lomb USA) corneal topography revealed inferior corneal ectasia with corneal astigmatism of $0.50 \mathrm{D}$ in the right eye. The thinnest point pachymetry of the right eye was $397 \mu$ and the maximum keratometric power (P-Kmax) was 50.I diopter (D) (Fig. Ia) (Table 2). In the pre-CXL corneal topography of the left eye, an inferotemporal corneal ectasia and corneal astigmatism of $3.5 \mathrm{D}$ was observed. The thinnest point pachymetry of the left eye was $382 \mu$, and the maximum keratometric power (P-Kmax) was 52.I D (Fig. Ib) (Table 2). In the $8^{\text {th }}$ month after CXL scanning, computerized corneal topography (Sirius 3D Rotating Scheimpflug Camera-Topography System Costruzione Strumenti Of talmici,
Florence, Italy) exhibited inferior corneal ectasia with corneal astigmatism of $0.75 \mathrm{D}$ in the right eye. The thinnest point pachymetry of the right eye was $425 \mu$, and P-Kmax was 5I.I D (Table 2). These values were similar to that of pre-CXL corneal topography (Fig. 2b). However, there was a progress of inferotemporal corneal ectasia matching with separated wound lips in the slit lamp examination in the corneal topography of the left eye (Fig. 3a, b). Even though the thinnest point pachymetry of the left eye was similar to the pre-CXL value $(395 \mu)$, the increase of P-Kmax (57.16 D) was remarkable (Fig. 3c) (Table 2). Additionally, the anterior segment optic coherence tomography (AS-OCT) shows the separated wound lips (Fig. 3d, e).

\section{Discussion}

The RK method used to treat mild to moderate myopia caused a hyperopic shift, exacerbated corneal ectasia and corneal instability in the long-term and was abandoned in the early 1990s (3). Even though Utine et al. (II) presented that RK surgery was a reasonable option for the rehabilitation of keratoconic corneas in the early or moderate stages, there were frequently unfavorable results for treating keratoconic

Table I. Refractive errors - best corrected distance visual acuity values

\begin{tabular}{lcccc} 
Eye & Pre - CXL RE & Post - CXL RE & Pre - CXL BCVA & Post - CXL BCVA \\
\hline Right & - I.50D sp -2.00D cyl & $-3.00 \mathrm{sp}-1.50 \mathrm{D}$ cyl & 0.9 Snellen & 0.9 Snellen \\
Left & $-0.50 \mathrm{D} \mathrm{sp}-2.00 \mathrm{D} \mathrm{cyl}$ & $+1.00 \mathrm{sp}-2.50 \mathrm{D} \mathrm{cyl}$ & 0.9 Snellen & $0.6 *$ Snellen \\
\hline
\end{tabular}

CXL: corneal collagen crosslinking; RE: refractive error; BCVA: best-corrected visual acuity values; $\mathrm{D}$ : diopters *no improvement with refraction.

Table 2. Computerized corneal topography values

\begin{tabular}{lcccc} 
Eye & Pre - CXL Kmax & Post - CXL Kmax & Pre - CXLTP & Post - CXLTP \\
\hline Right & 50.1 D & 5I.I D & $397 \mu$ & $425 \mu$ \\
Left & 52.1 D & $57.16 \mathrm{D}$ & $382 \mu$ & $395 \mu$ \\
\hline
\end{tabular}

CXL: corneal collagen crosslinking;TP: thinnest point pachymetry; Kmax: maximum keratometric power; D: diopters.

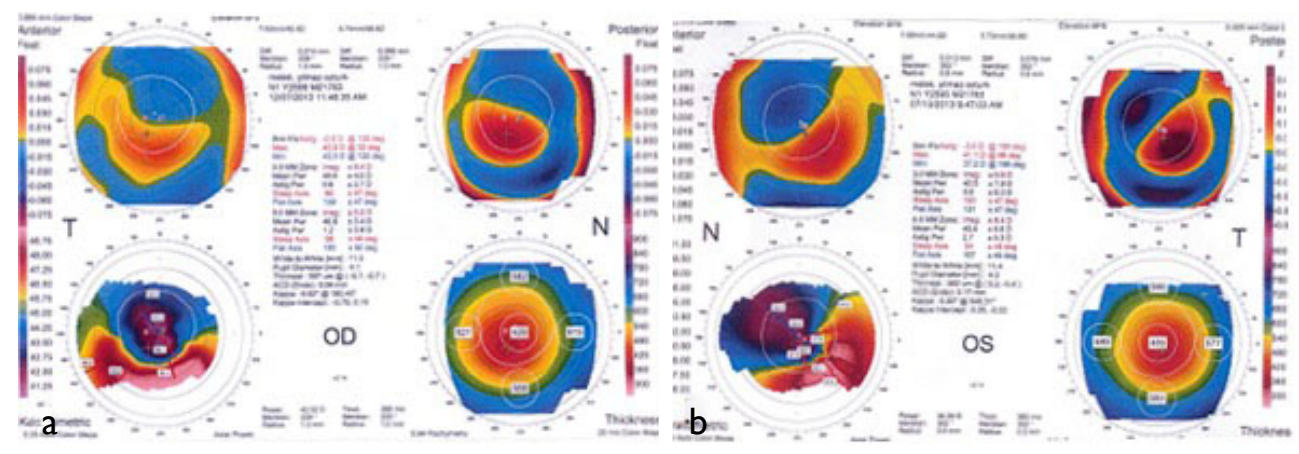

Figure I. (a) Corneal Topography of right eye (b) Pre-CXL Corneal Topography of the left eye. 

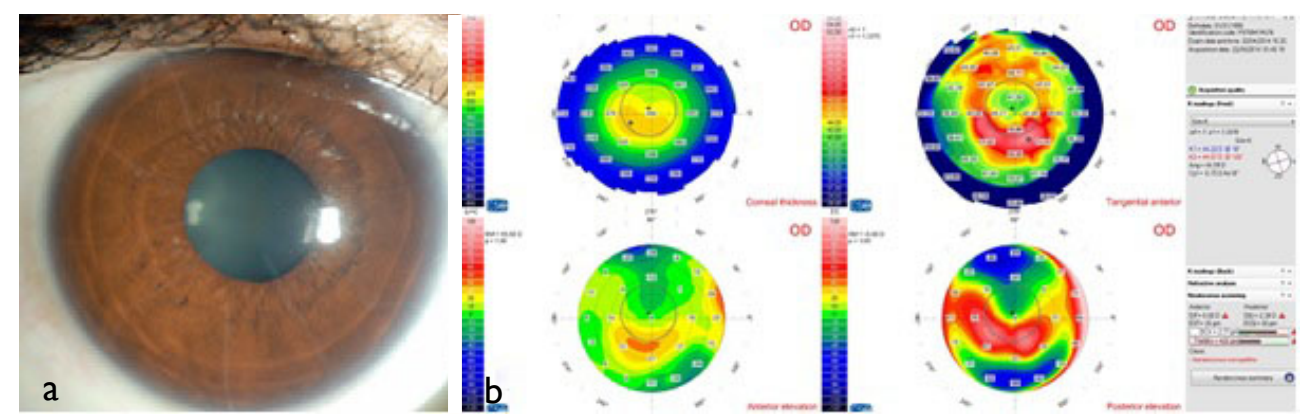

Figure 2. (a) Eight well-healed RK scars in the right eye (b) Corneal Topography of right eye.
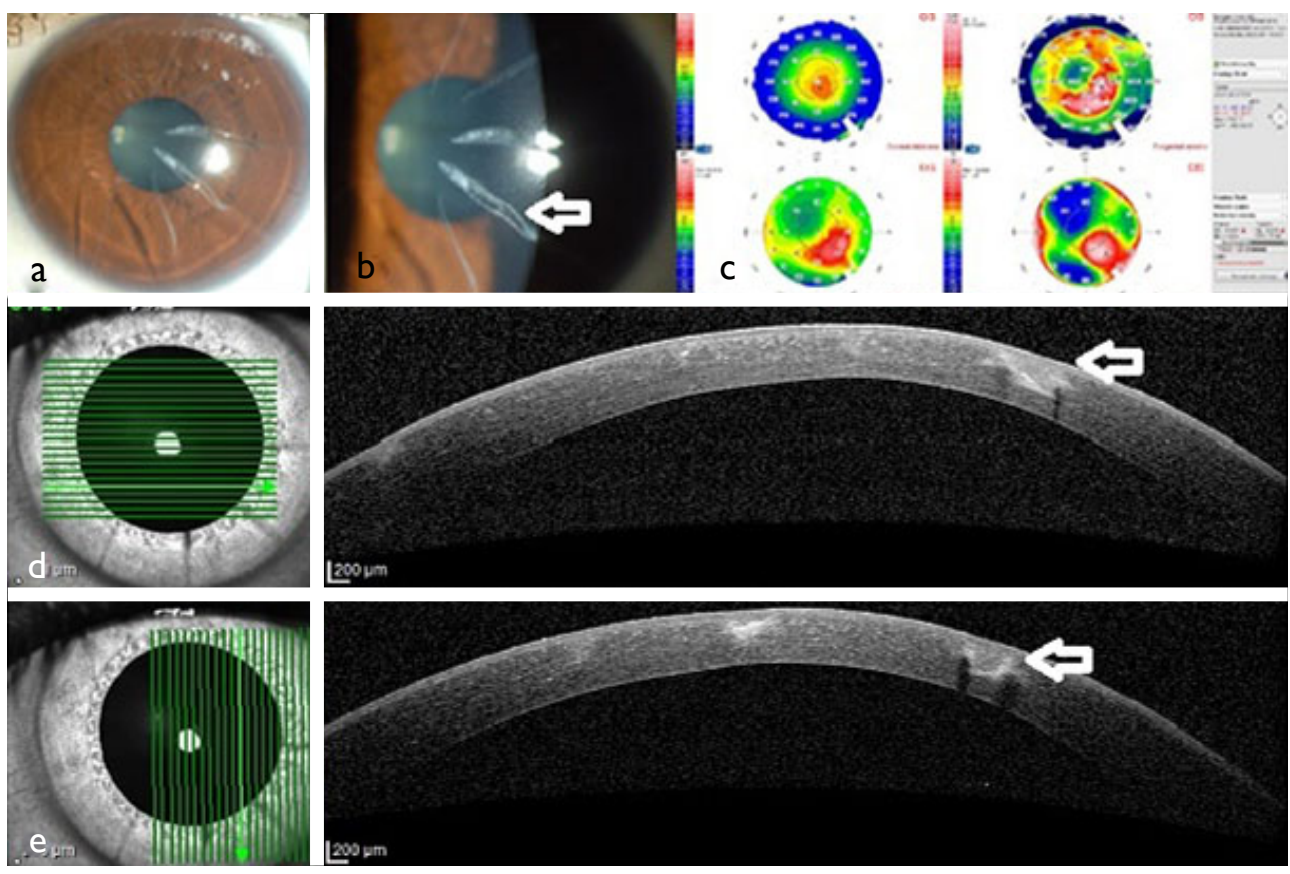

Figure 3. (a) 10 RK incisions in the left eye (b) 2 RK incisions had separated wound lips in temporal part (white arrow) (c) corneal topography of the left eye: progress of inferotemporal corneal ectasia matching with separated wound lips (d, e) AS-OCT shows the separated wound lips.

patients with RK in the literature, (4-6, 9) and exacerbation of corneal ectasia was particularly reported as a complication since biomechanical instability is a crucial component of $\mathrm{KC}$. Thus, RK-induced corneal weakening and biomechanical instability could be responsible for this exacerbation $(7,12)$. Laser in situ keratomileusis (LASIK), photorefractive keratectomy, double-concentric corneal sutures and implantable collamer lens were reported strategies for managing postRK refractive errors. However, the reported results are variable and unpredictable. The long-term stability is controversial (13-16). CXL was shown to be effective and safe for preventing the progress of keratectasia in keratoconic corneas and corneal ectasias that arose from the LASIK procedure. With CXL, there is a mild flattening of the cornea, a decrease of refractive error, and an increase in visual acuity (17). Although there were limited data performing CXL after RK, Elbaz et al. (18) showed that CXL is a safe and effective method to restore corneal stability in eyes with a history of RK. On the other hand, their patients had no history of keratectasia like the patient described in this report. Furthermore, Mazzotta et al. (6) claimed that CXL is a promising option for managing keratoconic patients previously treated with RK. They hypothesized that CXL stiffened collagen in the anterior and midstroma, increased interlamellar connections, and therefore, the main effect of cross-linking might be on keratoconus. According to their hypothesis, (6) the CXL effect failed to reach the depths of the reach that RK has. The present case report showed that performing CXL on keratoconic patient treated with RK could even accelerate the exacerbation. Similarly, in the literature, $(4-6,9)$ exacerbated corneal ectasia is a possible complication of RK, particularly in keratoconic corneas. One possible explanation for the acceleration of the keratoconic progression after RK is that the cross-linking of collagen fibers may stretch the 
wound lips of RK. Thus, the CXL effect probably does not reach the pathological area, (6) and this may result in newonset instability.

Although we thought that $\mathrm{CXL}$ is the main reason for exacerbation, loosening of the incisional scars could change the corneal topography of the current patient. In the current case report, the pre- and post-CXL corneal topography methods differ, which is an important limiting factor because it may affect the measurements. Thus, we could not provide an answer regarding whether the progression - detected in the eighth month after CXL - was caused by the CXL treatment or whether it was continued progression.

In conclusion, we thought that applying CXL on keratoconic patient previously treated with RK should be questioned. Evaluation of larger series with longer follow-up is needed to provide further information on the potential efficacy of CXL in keratoconic corneas treated with RK.

\section{Disclosures}

Informed consent: Written informed consent was obtained from the patient for the publication of the case report and the accompanying images.

Peer-review: Externally peer-reviewed.

Conflict of Interest: None declared.

Authorship Contributions: Involved in design and conduct of the study (MOC, KB); preparation and review of the study (MOC, $\mathrm{KB})$; data collection (MOC, KB).

\section{References}

I. Krachmer JH, Feder RS, Belin MW. Keratoconus and related noninflammatory corneal thinning disorders. Surv Ophthalmol 1984;28:293-322. [CrossRef]

2. Rabinowitz YS. Keratoconus. Surv Ophthalmol 1998;42:297319. [CrossRef]

3. Waring GO 3rd, Lynn MJ, Nizam A, Kutner MH, Cowden JW, Culbertson W, et al. Results of the Prospective Evaluation of Radial Keratotomy (PERK) Study five years after surgery. The Perk Study Group. Ophthalmology 1991;98:I 164-76. [CrossRef]

4. Wellish KL, Glasgow BJ, Beltran F, Maloney RK. Corneal ectasia as complication of repeated keratotomy surgery. J Refract Corneal Surg 1994;10:360-4.

5. Shaikh S, Shaikh NM, Manche E. latrogenic keratoconus as a complication of radial keratotomy. J Cataract Refract Surg
2002;28:553-5. [CrossRef]

6. Mazzotta C, Baiocchi S, Denaro R, Tosi GM, Caporossi T. Corneal collagen cross linking to stop corneal ectasia exacerbated by radial keratotomy. Cornea 201 I;30:225-8. [CrossRef]

7. Waring GO 3rd, Lynn MJ, McDonnell PJ. Results of the Prospective Evaluation of Radial Keratotomy (PERK) Study 10 Years After Surgery. Arch Ophthalmol 1994; I 12:1298-308. [CrossRef]

8. Mamalis N, Montgomery S, Anderson C, Miller C. Radial keratotomy in a patient with keratoconus. Refract Corneal Surg 1991;7:374-6.

9. Durand L, Monnot JP, Burillon C, Assi A. Complications of radial keratotomy: eyes with keratoconus and late wound dehiscence. Refract Corneal Surg 1992;8:3 I I-4.

10. Grandon SC, Weber RA. Radial keratotomy in patients with atypical inferior steepening. J Cataract Refract Surg 1994;20:381-6. [CrossRef]

I I. Utine CA, Bayraktar S, Kaya V, Kucuksumer Y, Eren H, Perente I, et al. Radial keratotomy for the optical rehabilitation of mild to moderate keratoconus: more than 5 years' experience. Eur J Ophthalmol 2006; 16:376-84. [CrossRef]

12. Deitz MR, Sanders DR, Raanan MG, DeLuca M. Long-term (5to 12-year) follow-up of metal-blade radial keratotomy procedures. Arch Ophthalmol 1994; I 12:6 14-20. [CrossRef]

13. Oral D, Awwad ST, Seward MS, Bowman RW, McCulley JP, Cavanagh HD. Hyperopic laser in situ keratomileusis in eyes with previous radial keratotomy. J Cataract Refract Surg 2005;3 I:| 56I-8. [CrossRef]

14. Joyal H, Grégoire J, Faucher A. Photorefractive keratectomy 144 to correct hyperopic shift after radial keratotomy. J Cataract Refract Surg 2003;29:1502-6. [CrossRef]

15. Nosé W, Endriss D, Forseto AS. Corneal suture for the correction of hyperopia following radial keratotomy. J Refract Surg 2007;23:523-7. [CrossRef]

16. Kamiya K, Shimizu K. Implantable Collamer lens for hyperopia after radial keratotomy. J Cataract Refract Surg 2008;34:14034. [CrossRef]

17. Li N, Peng XJ, Fan ZJ. Progress of corneal collagen cross-linking combined with refractive surgery. Int J Ophthalmol 20।4;7: I5762.

18. Elbaz U, Yeung SN, Ziai S, Lichtinger AD, Zauberman NA, Goldich $\mathrm{Y}$, et al. Collagen crosslinking after radial keratotomy. Cornea 20|4;33:|3|-6. [CrossRef] 